\title{
Cenário atual e perspectiva da ciência e da tecnologia na Bahia*
}

\section{The present scenery and the science and the technology perspective of Bahia}

\author{
CLEILZA FERREIRA ANDRADE**
}

*** Diretora Geral da FAPESB. Governo do Estado da Bahia

\begin{abstract}
* Conferência proferida no Instituto de Ciências da Saúde, UFBA, em 16 de outubro de 2001, por ocasião da inauguração das novas instalações da Biblioteca Prof. Penildon Silva e do Auditório Profa. Ophélia B. Gaudenzi.
\end{abstract}

Constitui-se em marco histórico da Ciência e Tecnologia (C\&T) no Estado, a criação da Fundação de Amparo à Pesquisa da Bahia (FAPESB), recorrente reivindicação da comunidade acadêmica, cuja lei foi sancionada pelo governador César Borges, em 27 de agosto de 2001.

Referenciada em diagnósticos e proposições do Programa de Inovação em Áreas Estratégicas - recém-elaborado por iniciativa e coordenação geral da Superintendência de Apoio ao Desenvolvimento Científico e Tecnológico (CADCT, sigla mantida do período institucional do órgão na condição de Centro) -, a criação da FAPESB respalda-se, sobretudo, no aprendizado institucional do Centro/da Superintendência, ao longo dos seus 10 (dez) anos de atuação.

O CADCT, desde os seus primórdios, concebeu-se como um embrião da futura Fundação e pautou suas ações e seu desempenho nos mesmos parâmetros e critérios de atuação das Fundações de Amparo à Pesquisa existentes nos demais Estados brasileiros, a exemplo da FAPESP São Paulo, FAPERJ - Rio de Janeiro, FAPERGS - Rio Grande do Sul, FACEPE - Pernambuco, FAPEAL Alagoas e similares.

Registre-se, aliás, que a Bahia, que teve a primeira Fundação de Amparo à Pesquisa do Brasil - a FUNDEC, criada pelo educador Anísio Teixeira em dezembro de 1950, a qual, após viver um período áureo, perdeu paulatinamente o seu vigor, vindo a ser extinta em 1974 -, é um dos últimos Estados brasileiros a integrar-se à rede nacional das FAP's - como se convencionou chamar essa malha institucional de apoio à pesquisa no Brasil, que se constrói espelhada na bem sucedida atuação da FAPESP. São Paulo, sob os estímulos da Constituinte de 1988 e das Constituições Estaduais de 1989.

Integrando-se a esse framework institucional, o CenFAPESB - Fundação de Amparo à Pesquisa do Estado da Bahia

Colina de São Lázaro, nº 203 - Federação 40210-720 - Salvador, Bahia, Brasil

e-mail: cleilza@fapesb.ba.gov.br tro define sua função e seus objetivos, estabelecendo sua missão básica: 
Definir politicas, prioridades e instrumentos para conceder apoio às atividades cientificas e tecnológicas do Estado.

Similarmente, a sua agenda de compromissos compreende, abrangendo o apoio a todas as atividades acadêmicas e de pesquisa contempladas pelas instituições congêneres, as seguintes modalidades de apoio:
a) Projetos
b) Pesquisa em desenvolvimento
c) Intercâmbio acadêmico
d) Montagem e modernização de labora- tórios
e) Informatização e modernização de cen- tros de informação e bibliotecas
f) Capacitação de recursos humanos
g) Realização e participação em eventos.

Atuando em função de prioridades prédefinidas e aprovadas pelo Conselho Estadual de Ciência e Tecnologia, o Centro/a Superintendência buscou dinamizar as atividades científicas e tecnológicas do Estado, visando, principalmente, a capacitação de recursos humanos, o fortalecimento de infra-estrutura laboratorial, a modernização e informatização de bibliotecas, direcionando seus investimentos para as seguintes áreas prioritárias:

I - Setores com tecnologia de forte impacto sobre a base produtiva
a) Química Fina e Inorgânica
b) Biotecnologia
c) Novos Materiais
d) Informática/software

II - Grandes vetores de consolidação da economia baiana
a) Química e Petroquímica
b) Metalurgia e Mineroindústria
c) Agroindústria

III - Atividades tecnológicas voltadas para educação

IV - Saúde pública, imunoprofilaxia e toxicologia

\section{V - Gestão e politica de C\&T}

Aos investimentos realizados nesses segmentos e grandes áreas de atividades selecionadas em função da dinâmica econômica do Estado e das vocações consolidadas ou potenciais de capacitação cientifico-tecnológica local, somaram-se a implementação de grandes projetos cooperativos com as agências federais de C\& T nos âmbitos dos Ministérios de Ciência e Tecnologia (MCT), da Educação (MEC), do Desenvolvimento, Indústria e Comércio Exterior (MDIC) e a parceria com um significativo rol de programas e projetos locais, que vêm sendo desenvolvidos pelo CADCT e serão assumidos e fortalecidos na Fundação. Entre eles se destacam os seguintes programas/projetos cooperativos:

- Projeto Nordeste de Pesquisa e Pós-Graduação - CAPES/SEMTEC-MEC

Estimula e apoia o fortalecimento e a capacitação dos cursos de pós-graduação (Mestrado/Doutorado) e os grupos emergentes de pesquisa.

- Programa de treinamento de professores do 2。 grau em Ciência e Matemática - PróCiências - CAPES/SEMTEC-MEC

Objetiva o treinamento de professores do $2^{\circ}$ grau nas áreas de Matemática, Física, Química e Biologia.

- Redes Cooperativas de Pesquisa RECOPE-FINEP/MCT

Visa a articulação de redes cooperativas de pesquisa que compartilham tecnologias, recursos humanos e materiais, envolvendo parcerias acadêmicas e empresariais.

- Informação e Comunicação para Ciência e Tecnologia - PROSSIGA-IBICT/ CNPq-MCT

- Programa Incubadoras de Empresas IEL/FIEB

- Programa Bahia Design - IEL/FIEB e Associação Baiana de Designers

- SOFTEX 2000 - MCT/Universidades/Empresas.

Especial registro merece ser feito à iniciativa do CADCT para dotar o Estado de programas mobilizadores nas áreas de Qualidade e Produtividade e de Design - estratégicas para a modernização e elevação do potencial competitivo das 
atividades econômicas da Bahia, sempre na perspectiva do seu papel de indutor e apoiador dessas ações que, uma vez viabilizadas, foram transferidas para locus institucionais com perfis adequados à sua implementação (IEL/FIEB e Associação Baiana de Designers, que congrega os principais designers da Bahia).
Neste último qüinqüênio, que abrange a maior concentração de recursos concedidos pelo CADCT, graças à visão e sensibilidade superiores do Secretário Luís Carreira, foram investidos, por modalidade de apoio e áreas do conhecimento, os valores absolutos e percentuais discriminados nas figuras subseqüentes:

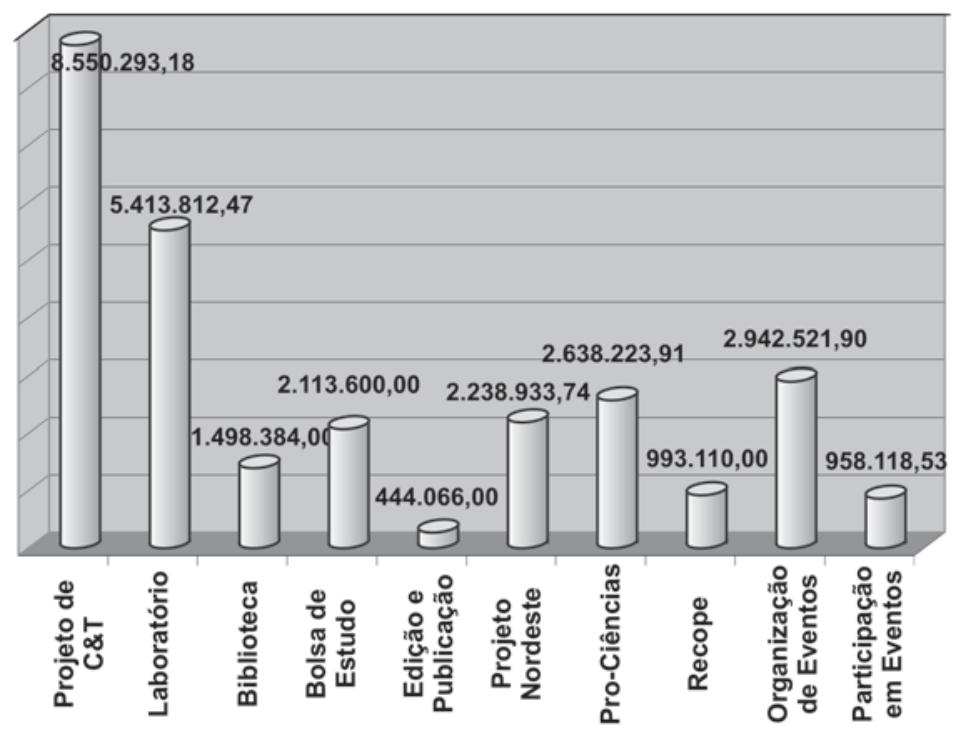

FIGURA 1 - Investimento por modalidade de apoio - 1996-200 (R \$ 1,00) FONTE - Dados primários. CADCT/SEPLANTEC, 2002.

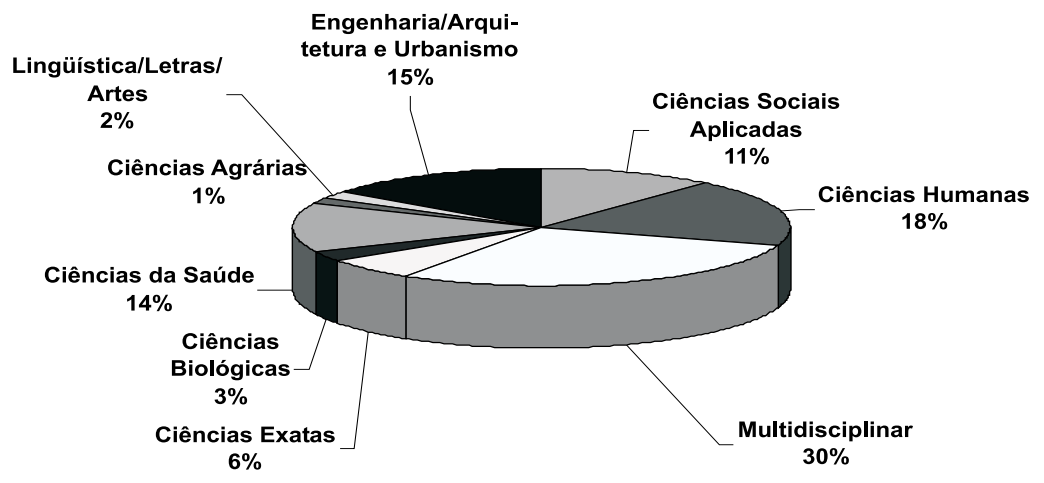

FIGURA 2 - Investimento por área de conhecimento - 1996-2000 (R\$1,00) FONTE - Dados primários. CADCT/SEPLANTEC, 2002. 
Compreensivelmente, significativa parcela desses recursos contemplou projetos e atividades das áreas de saúde humana e animal. Essas áreas, além de integrarem as prioridades do CADCT, contam com grupos de pesquisa consolidados e reconhecidos como de excelência pelas agências nacionais de C\&T e instituições de ensino e pesquisa, sobretudo em nível dos cursos de pós-graduação avaliados entre os melhores do país, como se vê no QUADRO 1.

QUADRO 1

Apoio na área de saúde

(1999/2002)

\begin{tabular}{|c|c|c|}
\hline OBJETO & INSTITUIÇÃO & $\operatorname{VALOR}(\mathrm{R} \$)$ \\
\hline Implantação do Laboratório de Diagnóstico e Pesquisa das & UFBA - Escola de Medicina & \\
\hline Leishmanioses nos Animais do Estado da Bahia & Veterinária & $60.000,00$ \\
\hline Implantação do CAISA para Atendimento ao Adolescente & UFBA - Faculdade de Medicina & $20.257,66$ \\
\hline Infecção Parasitária e Fatores Associados para o Desenvolvimento & & \\
\hline Cognitivo de Escolares & UFBA - Instituto de Saúde Coletiva & $30.000,00$ \\
\hline $\begin{array}{l}77^{\text {th }} \text { General Session and Exhibition of the Association } \\
\text { for Dental Research }\end{array}$ & UEFS & $3.129,00$ \\
\hline Ninth International Conference on Human Retrovirology: HTLV & $\begin{array}{l}\text { UFBA - Hospital Universitário } \\
\text { Prof. Edgard Santos }\end{array}$ & $5.300,00$ \\
\hline Determinação da Densidade Populacional de Aedes aegypti: Estudo & & \\
\hline Comparativo entre Métodos Tradicionais e uma Armadilha Especial & UFBA - Instituto de Saúde Coletiva & $80.589,00$ \\
\hline Avaliação da Percepção dos Pediatras sobre a Atenção & & \\
\hline Médica ao Adolescente & UFBA - Faculdade de Medicina & $5.350,00$ \\
\hline Aquisição de Software Especifico para o Seqüenciador & & \\
\hline Automático de DNA & UFBA - Instituto de Ciências da Saúde & $34.000,00$ \\
\hline $\begin{array}{l}\text { Programa de Treinamento Avançado em Técnicas } \\
\text { de Biologia Molecular }\end{array}$ & UFBA - Instituto de Ciências da Saúde & $3.230,00$ \\
\hline Encontro Norte e Nordeste sobre Anemias e Parasitoses & UNEB & $8.725,00$ \\
\hline Efeito do Fator Estimulador de Colônias de Granulócitos e & & \\
\hline Macrófagos Recombinantes no Tratamento, na Resposta & UFBA - Hospital Universitário & \\
\hline Imunológica e na Vacinação da Leishmaniose & Prof. Edgard Santos & $50.000,00$ \\
\hline $\begin{array}{l}\text { I Congresso Baiano de Patologia do Trato Genital Inferior e } \\
\text { Colposcopia }\end{array}$ & $\begin{array}{l}\text { Sociedade Baiana de Patologia } \\
\text { Cervical Uterina e Colposcopia }\end{array}$ & $15.000,00$ \\
\hline II Congresso Brasileiro de Enfermagem Obstétrica e Neonatal & UFBA - Escola de Enfermagem & $1.450,00$ \\
\hline $\begin{array}{l}\text { XIII Jornada de Estudos Clinicos e Sociais do Centro de Estudos e } \\
\text { Terapia do Abuso de Drogas }\end{array}$ & $\begin{array}{l}\text { UFBA - Centro de Estudos e } \\
\text { Terapia do Abuso de Drogas / } \\
\text { Associação Baiana de Apoio à } \\
\text { Prevenção, Terapia, Estudos e } \\
\text { Pesquisas do Abuso de Drogas }\end{array}$ & $7.500,00$ \\
\hline IV Congresso Brasileiro de Ultra-Sonografia & Hospital Estadual de Serrinha & $2.200,00$ \\
\hline $\begin{array}{l}\text { Implementação dos Laboratórios Referência em Bacteriologia e } \\
\text { Virologia Animal }\end{array}$ & $\begin{array}{l}\text { UFBA - Instituto de Ciências } \\
\text { da Saúde }\end{array}$ & $170.000,00$ \\
\hline
\end{tabular}




\begin{tabular}{|c|c|c|}
\hline OBJETO & INSTITUIÇÃO & $\operatorname{VALOR}(\mathrm{R} \$)$ \\
\hline $\begin{array}{l}\text { Estágio de Capacitação no Serviço de Farmacocinética Clinica no } \\
\text { Hospital Universitário da Universidade de Alicante }\end{array}$ & UFBA - Faculdade de Farmácia & $1.501,00$ \\
\hline Estudo Epidemiológico do Complexo Teniase-Cisticercose & UFBA - Faculdade de Medicina & $76.643,00$ \\
\hline $\begin{array}{l}\text { Reunião da Association de Coopération pour le Développement } \\
\text { des Services de Structures Sanitaires }\end{array}$ & $\begin{array}{l}\text { UFBA - Centro de Estudos e Terapia } \\
\text { do Abuso de Drogas / Associação } \\
\text { Baiana de Apoio à Prevenção, } \\
\text { Terapia, Estudos e Pesquisas do } \\
\text { Abuso de Drogas }\end{array}$ & $4.600,00$ \\
\hline $4^{\text {th }}$ Tropical Medicine Research Meeting & $\begin{array}{l}\text { UFBA - Hospital Universitário } \\
\text { Prof. Edgard Santos }\end{array}$ & $15.040,00$ \\
\hline $\begin{array}{l}\text { Influência do Zinco sobre o Controle Central de Aspectos de } \\
\text { Homeostasia Hidroeletrolitica }\end{array}$ & UFBA - Instituto de Ciências da Saúde & $30.000,00$ \\
\hline $\begin{array}{l}\text { Programa de Investimento na Qualificação Acadêmica do Insti- } \\
\text { tuto de Ciências da Saúde / Programa de Educação à Distância }\end{array}$ & UFBA - Instituto de Ciências da Saúde & $80.000,00$ \\
\hline Infecção pelo HTLV-I na Bahia: Linfomas Associados ao HTLV-I & $\begin{array}{l}\text { UFBA - Hospital Universitário } \\
\text { Prof. Edgard Santos }\end{array}$ & $89.000,00$ \\
\hline $\begin{array}{l}\text { Curso de Especialização em Radiologia no Hospital Johns Hopkins, } \\
\text { Baltimore }\end{array}$ & $\begin{array}{l}\text { UFBA - Hospital Universitário } \\
\text { Prof. Edgard Santos }\end{array}$ & $6.000,00$ \\
\hline $\begin{array}{l}\text { IX Conferência Internacional sobre Retrovirologia Humana } \\
- \text { HTLV }\end{array}$ & FIOCRUZ / CPqGM & $3.550,00$ \\
\hline XVI Congresso da Sociedade Brasileira de Imunologia & FIOCRUZ / CPqGM & $10.000,00$ \\
\hline $\begin{array}{l}\text { Desenvolvimento de Leitora de Densidade Óptica para Método } \\
\text { Elisa }\end{array}$ & FIOCRUZ / CPqGM & $25.000,00$ \\
\hline Simpósio Internacional de Patogênese em Doenças Tropicais & FIOCRUZ / CPqGM & $5.000,00$ \\
\hline 19 Meeting of the Institute of Human Virology & FIOCRUZ / CPqGM & $1.995,00$ \\
\hline $\begin{array}{l}\text { Curso de Adequação Fisica e de Procedimentos Laboratoriais às } \\
\text { Normas de Biossegurança }\end{array}$ & FIOCRUZ / CPqGM & $5.000,00$ \\
\hline $\begin{array}{l}\text { Estágio Técnico na Unidade INSERM } 196 \text { - Instituto Curie, } \\
\text { Paris }\end{array}$ & FIOCRUZ / CPqGM & $2.000,00$ \\
\hline $\begin{array}{l}\text { Estudo Epidemiológico da Leishmaniose Visceral Humana (LVH) } \\
\text { na Área Endêmica de Jequié, Bahia }\end{array}$ & FIOCRUZ / CPqGM & $118.941,00$ \\
\hline $\begin{array}{l}\text { Diversidade Filogenética do Virus Linfotrópico para Células } \\
\text { T Humanas do Tipo I / II (HTLV-I e HTLV-II) na Bahia: Impacto } \\
\text { na Origem e Evolução da Epidemia, no Diagnóstico e na Patogênese } \\
\text { da Doença }\end{array}$ & FIOCRUZ / CPqGM & $120.000,00$ \\
\hline VI Simpósio Internacional sobre HTLV no Brasil & FIOCRUZ / CPqGM & $20.000,00$ \\
\hline $\begin{array}{l}\text { Third Joint Meeting of the International Cytokine Society and } \\
\text { International Society and Interferon Research }\end{array}$ & FIOCRUZ / CPqGM & $1.789,00$ \\
\hline $\begin{array}{l}\text { XVI Reunião de Pesquisa Aplicada em Doença de Chagas / IV } \\
\text { Reunião Aplicada em Leishmanioses }\end{array}$ & FIOCRUZ / CPqGM & $4.356,00$ \\
\hline
\end{tabular}




\begin{tabular}{|c|c|c|}
\hline OBJETO & INSTITUIÇÃO & $\operatorname{VALOR}(\mathrm{R} \$)$ \\
\hline Leitora de Densidade Óptica para Teste Elisa - Fase II & UFBA / FIOCRUZ / CPqGM & $20.381,00$ \\
\hline $\begin{array}{l}\text { Controle da Leishmaniose Visceral: Desenvolvimento de } \\
\text { Uma Vacina Canina }\end{array}$ & FIOCRUZ / CPqGM & $63.840,00$ \\
\hline $\begin{array}{l}\text { Epidemiologia Molecular do Virus da Hepatite C (VHC) em } \\
\text { Salvador, Bahia }\end{array}$ & FIOCRUZ / CPqGM & $95.000,00$ \\
\hline IV Conferência Européia (Lisboa - Portugal) & $\begin{array}{l}\text { UFBA - Centro de Estudos e Terapia do } \\
\text { Abuso de Drogas }\end{array}$ & $1.619,32$ \\
\hline Curso de Especialização em Higiene Ocupacional & UFBA - Escola Politécnica & $1.762,00$ \\
\hline I Simpósio de Saúde e Meio Ambiente do Interior da Bahia & UFBA - Faculdade de Medicina & $4.504,50$ \\
\hline $\begin{array}{l}\text { Expansão do Laboratório de Imunidade Celular / Implementação } \\
\text { do Laboratório Avançado de Manuseio de Patógenos }\end{array}$ & $\begin{array}{l}\text { UFBA - Hospital Universitário } \\
\text { Prof. Edgard Santos }\end{array}$ & $14.381,00$ \\
\hline $\begin{array}{l}\text { IX Congresso da Organização de Farmacêuticos } \\
\text { Ibero-Latino-Americanos (OFIL) }\end{array}$ & UFBA - Faculdade de Farmácia & $3.892,00$ \\
\hline $\begin{array}{l}\text { Congresso Brasileiro de Pesquisa em Saúde da Criança } \\
\text { e do Adolescente }\end{array}$ & UFBA - Faculdade de Medicina & $1.100,00$ \\
\hline II Curso de Atualização em Citopatologia Ginecológica & UFBA - Faculdade de Medicina & $2.481,40$ \\
\hline V Congresso Internacional de Cardiologia & UFBA - Fundação Bahiana de Cardiologia & $30.000,00$ \\
\hline Projeto da Rede do Hospital Universitário Prof. Edgard Santos & $\begin{array}{l}\text { UFBA - Hospital Universitário } \\
\text { Prof. Edgard Santos }\end{array}$ & $200.000,00$ \\
\hline XIV Jornada Odontológica para Pacientes Especiais & $\begin{array}{l}\text { UFBA - Faculdade de Odontologia / } \\
\text { Associação Brasileira de Odontologia } \\
\text { - Seção Bahia }\end{array}$ & $6.944,31$ \\
\hline $\begin{array}{l}\text { Instalação e Funcionamento do Curso de Pós-Graduação em } \\
\text { Medicina no Pavilhão Magalhães Neto }\end{array}$ & $\begin{array}{l}\text { UFBA - Hospital Universitário } \\
\text { Prof. Edgard Santos }\end{array}$ & $80.000,00$ \\
\hline $\begin{array}{l}\text { Influência da Infecção pelo Schistosoma Mansoni no } \\
\text { Desenvolvimento de Asma Brônquica }\end{array}$ & $\begin{array}{l}\text { UFBA - Hospital Universitário } \\
\text { Prof. Edgard Santos }\end{array}$ & $42.700,00$ \\
\hline $\begin{array}{l}\text { Estudos Clinicos e Caracterização Histopatológica das Hepatites } \\
\text { Criptogênicas em Salvador, Bahia }\end{array}$ & $\begin{array}{l}\text { UFBA - Hospital Universitário } \\
\text { Prof. Edgard Santos }\end{array}$ & $67.976,00$ \\
\hline I Fórum Brasileiro sobre Adolescência & UFBA - Faculdade de Medicina & $10.000,00$ \\
\hline $\begin{array}{l}\text { Third Joint Meeting of the International Cytokine Society and } \\
\text { International Society and Interferon Research }\end{array}$ & UFBA - Instituto de Ciências da Saúde & $2.400,00$ \\
\hline $\begin{array}{l}\text { I Curso Internacional: Progressos no Diagnóstico das Parasitoses } \\
\text { dos Animais de Produção / Programa de Treinamento } \\
\text { para Terceiros Paises }\end{array}$ & UFBA - Escola de Medicina Veterinária & $6.904,00$ \\
\hline I Simpósio de Saúde e Meio Ambiente do Interior da Bahia & UFBA - Faculdade de Medicina & $4.290,00$ \\
\hline Conferência sobre Humanização do Parto e Nascimento & UFBA - Escola de Enfermagem & 948,00 \\
\hline Aquisição de Programa Upgrade para o DNA Sequencer & UFBA - Instituto de Ciências da Saúde & $22.000,00$ \\
\hline
\end{tabular}




OBJETO
Sistema de Informação sobre Agentes Teratogênicos (SIAT)
Retrovirus Humano: Determinação da Presença do Retrovirus
como Agente Causal de Diarréias em Crianças Hospitalizadas
Modernização e Atualização do Acervo da Biblioteca da Faculdade
de Farmácia
XXXVII Congresso da Sociedade Brasileira de Medicina Tropical
VIII Congresso Brasileiro de Adolescência e VII Congresso
Internacional de Saúde na Adolescência
IV Simpósio Internacional de Hepatite Viral

III Simpósio Latino-Americano de Identificação Humana

International Neuropsycological Society Meeting

XXIV Congresso Brasileiro de Cirurgia: Perspectivas Cirúrgicas para o Século XXI

$10^{\text {th }}$ International Conference on Human Retrovirology:

HTLV and Related Viruses

$10^{\text {th }}$ International Conference on Human Retrovirology:

HTLV and Related Viruses

Curso de Doutorado em Kinesiologia e Fisiatria

II Curso Internacional sobre Parasitoses dos Animais de Produção

$19^{\text {th }}$ International Papillomavirus Conference

I Curso de Epidemiologia Molecular em Doenças

Infecciosas Emergentes

Modernização do Laboratório de Virologia do Instituto de

Ciências da Saúde

IV Congresso Brasileiro Pediátrico de Endocrinologia

e Metabologia

Rotavirus Humano: Determinação da Presença de Rotavirus como Agente Causal de Diarréias em Crianças

Hospitalizadas - Etapa II

IV Simpósio Brasileiro de Pesquisa em Aids

Curso de Psicologia Médica sobre Acompanhamento de

Pacientes Terminais e de Pacientes com Dor Crônica
INSTITUIÇÃO

$\operatorname{VALOR}(\mathrm{R} \$)$

UFBA - Hospital Universitário

Prof. Edgard Santos

$73.290,00$

UFBA - Faculdade de Farmácia

$2.364,00$

UFBA - Instituto de Ciências da Saúde

$7.875,00$

UFBA - Faculdade de Farmácia

$27.950,00$

FIOCRUZ

$20.000,00$

UFBA - Faculdade de Medicina

$30.000,00$

Associação do Curso de Pós-Graduação em Medicina / UFBA - Hospital

Universitário Prof. Edgard Santos

UFBA - Instituto de Ciências da Saúde

$10.000,00$

$3.500,00$

Faculdade Ruy Barbosa

$1.516,00$

Associação Bahiana de Medicina

$4.820,00$

UFBA - Faculdade de Medicina

$3.844,00$

Fundação para o Desenvolvimento das Ciências / UFBA - Instituto

de Ciências da Saúde

$7.688,00$

Faculdade Adventista de Fisioterapia

$3.568,00$

UFBA - Escola de Medicina Veterinária

$3.482,00$

UFBA - Faculdade de Medicina

CPqGM

$5.000,00$

UFBA - Instituto de Ciências da Saúde

$45.000,00$

Associação do Curso de Pós-Graduação em Medicina

$8.000,00$

UFBA - Instituto de Ciências da Saúde

$12.000,00$

Sociedade Baiana de Infectologia

$10.000,00$

UFBA - Hospital Universitário

Prof. Edgard Santos / Associação

do Curso de Pós-Graduação

em Medicina

$3.000,00$ 
OBJETO

Avaliação Imunohistoquimica e Histométrica da Influência da Nicotina Associada ao Trauma de Oclusão Primário na Evolução da Periodontite Induzida em ratos

Influência do Zinco sobre o Controle Central de Aspectos da Homeostasia Hidroeletrolica - Etapa II

Estudo Comparativo dos Genótipos 1 e 3 do virus C (VHC) em Salvador, Nordeste do Brasil

Publicação do Manual Clinico de Teniase-Cisticercose

II Curso de Pós-Graduação em Gerência de Saúde

Centro de Referência para Atendimento Integrado Multidisciplinar de Individuos Infectados pelo Virus Linfotrópico de Células T Humanas - HTLV-I

Telecardio: Desenvolvimento e Implantação de Aplicações de Telemedicina para Cardiologia no Estado da Bahia

Course on Genetic Manipulation in Mice

Tópicos Avançados em Genética e sua Utilização na Prática Médica

Monitoramento de Micotoxinas em Bagaço de Cervada Utilizado na Alimentação do Rebanho Leiteiro no Estado da Bahia

XXVII Congresso Brasileiro de Medicina Veterinária

Seminário em Linfomas: Aspectos Clinicos, Histopatológicos e Moleculares

Montagem dos Laboratórios e Salas de Estudo do Curso de Pós-Graduação em Medicina

Programa de Qualificação Acadêmica do Instituto de Ciências da Saúde da UFBA

Análise Genômica Funcional de Células de Pacientes com

Diferentes Formas Clinicas de Leishmaniose Tegumentar em Jequié, Bahia

Infovias da Saúde - Rede de Saúde

Estudo Multidisciplinar das Deformidades Dentofaciais Congênitas e ou Hereditárias do Estado da Bahia
INSTITUIÇÃO

$\operatorname{VALOR}(\mathrm{R} \$)$

Fundação para o Desenvolvimento das Ciências

$20.061,00$

UFBA - Instituto de Ciências da Saúde/ Associação do Curso de Pós-Graduação em Medicina

$8.500,00$

UFBA - Hospital Universitário

Prof. Edgard Santos/ Associação do

Curso de Pós-Graduação em Medicina

$12.520,00$

UFBA - Hospital Universitário

Prof. Edgard Santos / Associação do

Curso de Pós-Graduação em Medicina

UFBA - Faculdade de Medicina /

Associação do Curso de Pós-Graduação em Medicina

$6.000,00$

Fundação para o Desenvolvimento da Ciência

$437.323,93$

UFBA - Fundação Bahiana

de Cardiologia

$133.399,00$

CPqGM / FIOCRUZ / FAPEX

$5.000,00$

UFBA - Hospital Universitário Prof. Edgard Santos / Associação do Curso de Pós-Graduação em Medicina

$8.000,00$

UFBA - Escola de Medicina Veterinária

$22.416,00$

UFBA - Escola de Medicina Veterinária

$4.850,00$

UFBA - Faculdade de Medicina /

Associação do Curso de Pós-Graduação em Medicina

$2.200,00$

UFBA - Faculdade de Medicina /

CPQGM

$39.000,00$

UFBA - Instituto de Ciências

da Saúde / FEP

$60.000,00$

CPqGM / Associação do Curso de Pós-Graduação em Medicina

$46.600,00$

UFBA - Faculdade de Medicina / Associação do Curso de Pós-Graduação em Medicina

$50.000,00$

UFBA - Hospital Universitário Prof. Edgard Santos e Faculdade de Odontologia / Associação do Curso de Pós-Graduação em Medicina 


\begin{tabular}{|llr|}
\hline OBJETO & INSTITUiÇÃO & VALOR(R\$) \\
\hline $\begin{array}{l}\text { Avaliação de Mecanismos de Ação de Drogas Extraidas de Plantas } \\
\text { Medicinais Nativas da Bahia, Brasil }\end{array}$ & $\begin{array}{l}\text { UFBA - Instituto de Ciências da } \\
\text { Saúde / FAPEX }\end{array}$ & $38.000,00$ \\
\hline TOTAL & $3.058 .425,67$ \\
\hline
\end{tabular}

FONTE - Dados primários. CADCT, 2001.

UFBA - Universidade Federal da Bahia; UEFS - Universidade Estadual de Feira de Santana; UNEB - Universidade do Estado da Bahia; FIOCRUZ - Fundação Osvaldo Cruz; CPqGM - Centro de Pesquisa Gonçalo Muniz; FAPEX - Fundação de Apoio à Pesquisa e Extensão.

Especial destaque merece ser dado aos principais projetos em execução sob a coordenação geral do CADCT, em razão do grande impacto espe- rado em nivel da dinamização econômica e da elevação da capacitação técnico-cientifica do Estado da Bahia (QUADRO 2).

\section{QUADRO 2}

Principais projetos em execução

(ano base 2001)

\begin{tabular}{|c|c|c|c|}
\hline PROJETOS & VALORES & PARCERIAS & BENEFICIADOS \\
\hline $\begin{array}{l}\text { Redes Cooperativas de Pesquisa } \\
\text { (RECOPE) }\end{array}$ & $2.000 .000,00$ & $\begin{array}{l}\text { FINEP } \\
\text { Universidades } \\
\text { Empresas }\end{array}$ & $\begin{array}{l}07 \text { redes em execução } \\
03 \text { redes conveniadas }\end{array}$ \\
\hline $\begin{array}{l}\text { Programa de Instalação de Doutores } \\
\text { (PRODOC) }\end{array}$ & $1.250 .000,00$ & $\begin{array}{l}\text { UFBA } \\
\text { UESC } \\
\text { UESB } \\
\text { UEFS } \\
\text { UNEB }\end{array}$ & 100 doutores beneficiados \\
\hline Programa de Iniciação Cientifica (PIBIC) & $869.400,00$ & $\begin{array}{l}\text { UFBA } \\
\text { UNEB }\end{array}$ & 300 bolsistas beneficiados \\
\hline UFBA em Campo & $474.000,00$ & UFBA & 125 bolsas / monitores beneficiados \\
\hline $\begin{array}{l}\text { Projeto Nordeste de Pesquisa e } \\
\text { Pós-Graduação (Pró-Nordeste) }\end{array}$ & $2.238 .933,74$ & $\begin{array}{l}\text { CAPES / MEC } \\
\text { UFBA } \\
\text { UESC } \\
\text { UESB } \\
\text { UNEB } \\
\text { UCSAL }\end{array}$ & $\begin{array}{l}02 \text { cursos de Doutorado } \\
11 \text { cursos de Mestrado } \\
14 \text { grupos emergentes de pesquisa } \\
19 \text { cursos de Especialização }\end{array}$ \\
\hline $\begin{array}{l}\text { Programa de Treinamento de Professores } \\
\text { em Ciências e Matemática (Pró-Ciências) }\end{array}$ & $2.638 .223,91$ & $\begin{array}{l}\text { CAPES / MEC } \\
\text { UFBA } \\
\text { UESC } \\
\text { UESB } \\
\text { UNEB } \\
\text { UEFS } \\
\text { UCSAL }\end{array}$ & 2.600 professores treinados \\
\hline $\begin{array}{l}\text { Núcleo de Desenvolvimento de Softwar } \\
\text { e para Exportação (SOFTEX) }\end{array}$ & $200.000,00$ & $\begin{array}{l}\text { SOFTEX - Salvador } \\
\text { MCT / CNPq }\end{array}$ & $\begin{array}{l}32 \text { empresas incubadas } \\
16 \text { empresas geradas } \\
14 \text { empresas certificadas - ISO } 9001 \\
08 \text { projetos apoiados }\end{array}$ \\
\hline
\end{tabular}




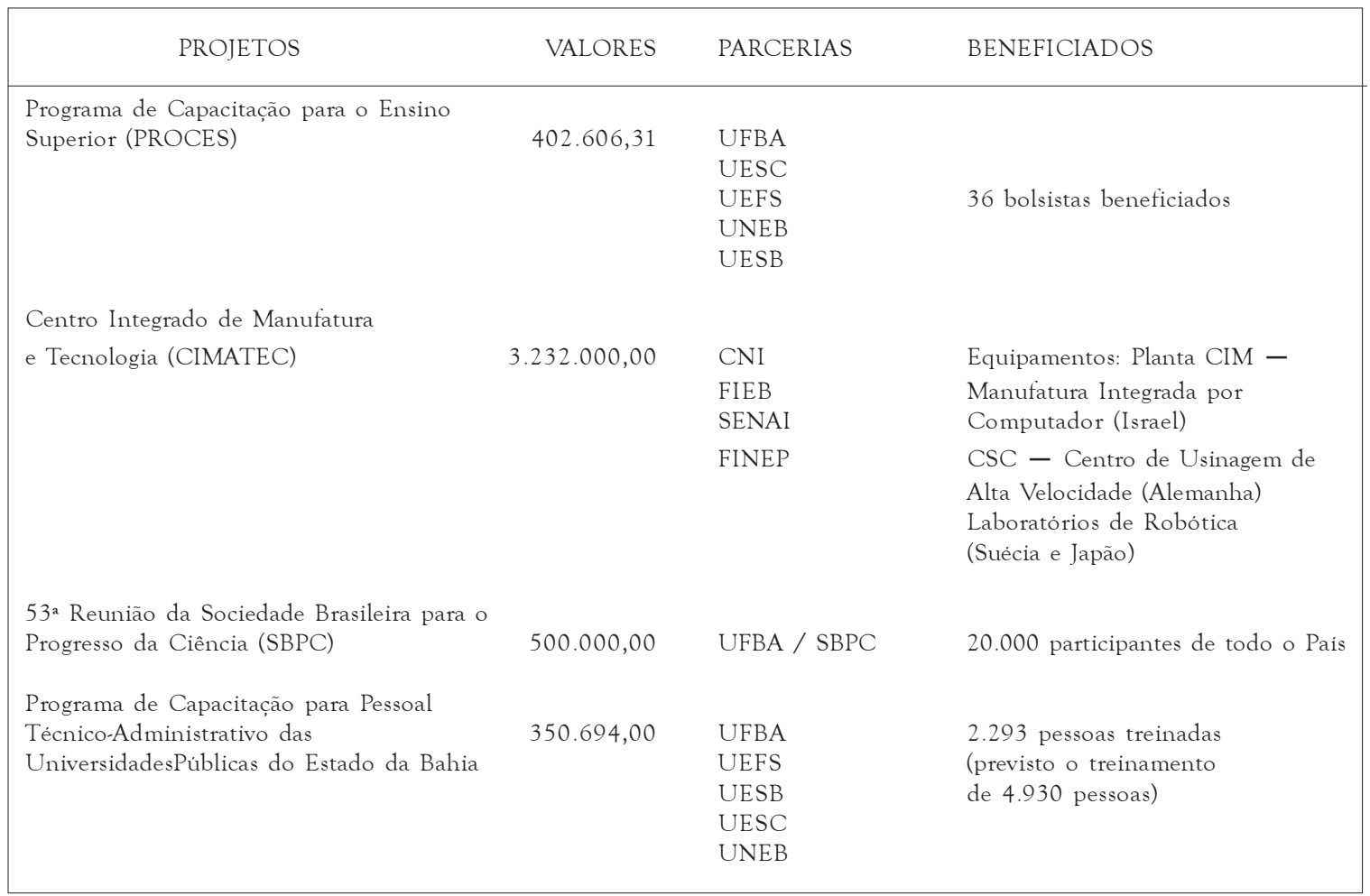

FONTE - CADCT. Dados primários.

Os investimentos feitos pelos Estados em Ciência e Tecnologia, no contexto da sociedade do conhecimento e da informação em que vivemos, são de fundamental importância para propiciar o ambiente favorável à dinamização econômica e ao diferencial competitivo que é a força motriz da empresa no mundo globalizado.

Torna-se cada vez mais factivel a suposição de que os produtos que usaremos daqui a dez anos não foram sequer concebidos até então. A constatação, registrada por Hawking (2001), de que a complexidade e a capacidade do computador dobram a cada 18 meses, induzindo a visão de que, a curto prazo, a inteligência eletrônica estará interconectada à inteligência biológica, ampara fortemente a possibilidade de ampliação do gap entre as nações de maior e menor grau de conhecimento, capacitação tecnológica, infra-estrutura informacional e de comunicação.

A sociedade do conhecimento inseriu o saber na base da dinâmica capitalista, e a sua agregação à produção, em maior ou menor escala, decide o poderio econômico e político das nações no amplo mundo capitalista.

Um dos maiores pensadores contemporâneos enfocou brilhantemente essa questão ao afirmar que: "O mundo já se dividiu entre fortes e fracos, ricos e pobres, e agora começa a se dividir entre os que sabem e os que não sabem”. *

Alie-se a isso o fato de que só a capacitação humana em larga escala poderá evitar a exclusão digital e a ignorância tecnológica que ameaça os povos menos desenvolvidos.

No Brasil, tradicionalmente, os investimentos no ensino superior, em infra-estrutura laboratorial e em instituições de pesquisa e desenvolvimento eram feitos pelo Governo Federal. À exceção do Estado de São Paulo, os Estados membros brasileiros, só muito recentemente e de forma

\footnotetext{
* Norbert Bobbio, em solenidade de recebimento de prêmio literário em Paris, 1998
} 
tímida, começaram a colocar a ciência e a tecnologia na agenda do seu desenvolvimento.

$\bigcirc$ próprio pais, que investe hoje em torno de $1,2 \%$ do seu produto interno bruto em C\&T, conforme dados do Ministério de Ciência e Tecnologia (MCT), mantém seu patamar de investimentos muito aquém dos 3\% a $4 \%$ dos investimentos feitos pelas nações mais desenvolvidas, como Estados Unidos, Japão, Alemanha, França e Inglaterra.

A universidade pública brasileira, que não consegue superar a inflexão de ser a universidade dos filhos das camadas mais favorecidos da população (2,3\% da mão-de-obra ativa que ganha acima de $\mathrm{R} \$ 3.600,00 /$ mês ocupa 25\% das vagas, contra 9,3\% de alunos oriundos de famílias com rendimentos de até $\mathrm{R} \$ 540,00 /$ mês que totalizam $67 \%$ da mão-de-obra ativa), amarga uma longa crise que vem comprometendo a qualidade do ensino e a produção de pesquisas.

Uma visão relativa dos orçamentos realizados por universidades americanas e brasileiras abre um amplo espaço para reflexão e análise QUADRO 3.

\section{QUADRO 3}

Investimentos: Universidades do Brasil e dos EUA

Maiores orçamentos para o ensino superior nos dois países em 2000 (em US\$)

\begin{tabular}{|llll|}
\hline \multicolumn{1}{c}{ E U A } & & \multicolumn{2}{c|}{ BRASIL } \\
\hline Harvard & 2,9 bilhões & USP & 529 milhões \\
Stanford & 2,6 bilhões & UFRJ & 301 milhões \\
Pensilvânia & 2,5 bilhões & UNESP & 295 milhões \\
MIT & 2,1 bilhões & UNICAMP & 239 milhões \\
Columbia & 1,8 bilhões & UFPB & 184 milhões \\
Cornell & 1,8 bilhões & UFMG & 171 milhões \\
Inst. de Tec. da Califórnia & 1,8 bilhões & UFBA & 161 milhões \\
& & UFF & 144 milhões \\
\hline
\end{tabular}

FONTE - The chronicle of higher education, FAPESP, UFBA, UFPB e UFF.

Refletindo essa problemática que envolve a universidade pública federal, os Estados membros paulatinamente aumentam seus investimentos no ensino de $3^{\circ}$ grau, visà- pela União. A situação na Bahia, que dispõe hoje de quatro Universidades Estaduais - UNEB, UESB, UESC e UEFS -, comporta-se conforme os dados que figuram no QUADRO 4.

\footnotetext{
QUADRO 4

Investimento por esferas de Governo

(ano-base 2000)
}

\begin{tabular}{|cccc|}
\hline \multicolumn{2}{|c|}{ GOVERNO DA BAHIA } & GOVERNO FEDERAL \\
INSTITUIÇÃO & $\begin{array}{c}\text { VALOR (US\$) } \\
\text { (milhões) }\end{array}$ & INSTITUIÇÃO & $\begin{array}{c}\text { VALOR (US\$) } \\
\text { (milhões) }\end{array}$ \\
\hline UNIVERSIDADES ESTADUAIS & 112 & UNIVERSIDADE FEDERAL DA BAHIA & 161 \\
\hline
\end{tabular}

FONTE - CADCT/UFBA. 
Esse avanço dos investimentos feitos pelos Estados membros é particularmente acentuado no Estado de São Paulo, dado o vigor financeiro da Fundação de Amparo à Pesquisa daquele Estado e o forte Programa de Bolsas de Estudo implementado, conforme expressa a FIG. 3
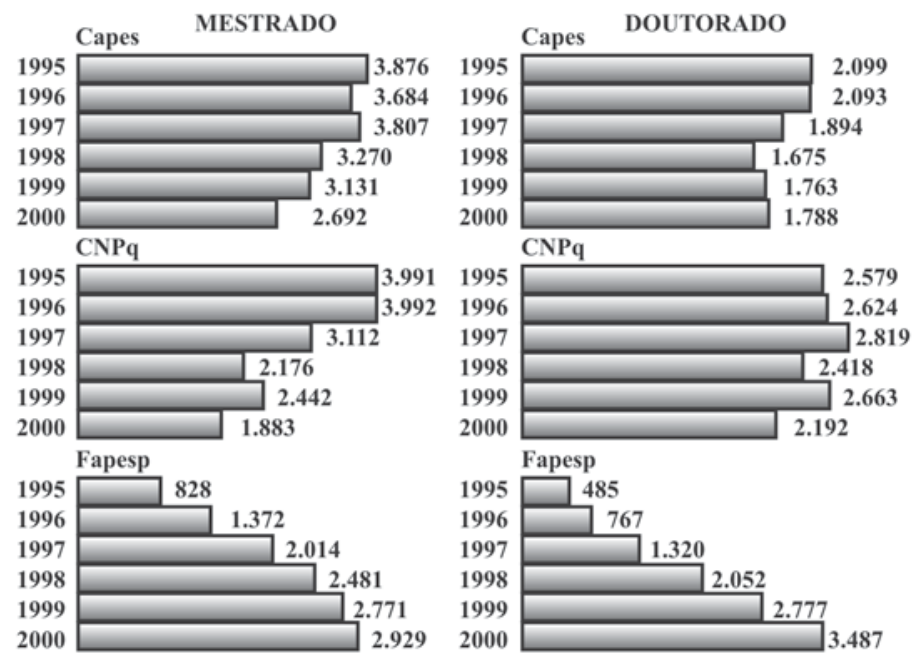

FIGURA 3 - Evolução do número de bolsas concedidas no Estado de São Paulo FONTE - Pesquisa, São Paulo, FAPESP, set./out. 2001

Considerando-se que os desniveis entre países em escala internacional reproduzem-se internamente em nivel inter- e intra-regional, favorecendo excepcionalmente, no caso brasileiro, os Estados do Sul e Sudeste, muito especialmente o Estado de São Paulo, eleva-se em dimensão e complexidade a necessidade de os Estados nordestinos definirem e implemen- tarem sólidas e competentes politicas de desenvolvimento científico-tecnológico e de capacitação de recursos humanos.

Os investimentos feitos pelas agências federais de apoio a $\mathrm{C} \& \mathrm{~T}$, especialmente $\mathrm{CNP}_{\mathrm{q}}$, FINEP e CAPES, são absurdamente concentrados nos Estados do Sul e Sudeste, conforme pode-se observar nas FIG. 4 e 5.

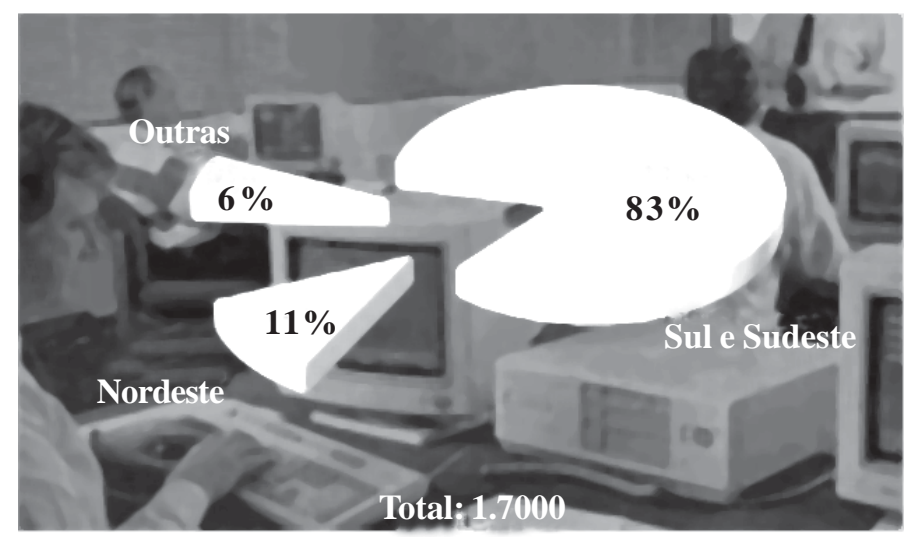

FIGURA 4 - Distribuição dos cursos de Mestrado e Doutorado no pais (1998) FONTE - Pesquisa, São Paulo, FAPESP, set./out. 2001. CNPq/MCT. 


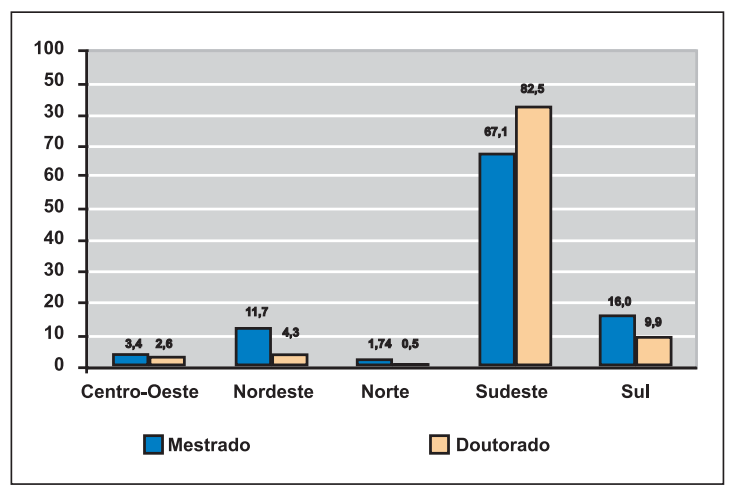

FIGURA 5 - Origem dos pesquisadores que recebem bolsas do CNPQ (ano-base 1998)

FONTE - CNPq/MCT.

O Estado de São Paulo, cuja Fundação de Amparo à Pesquisa tem, anualmente, orçamento correspondente em valores ao orçamento do $\mathrm{CNPq}$, que é destinado a atender a todo o País, recebe em torno de $48 \%$ a $50 \%$ dos recursos aplicados pelo CNPq. Trata-se, portanto, do pleno exercício de uma política de aguçamento das desigualdades regionais que penaliza fortemente Estados como a Bahia.

Sobretudo nesse contexto, a criação da Fundação de Amparo à Pesquisa do Estado da Bahia (FAPESB) é de importância estratégica para consolidar e impulsionar todo um lastro de capacitação cientifica e tecnológica no Estado.

No exercício de 2001, somando-se aos recursos do Tesouro Estadual os repasses do Governo Federal, através de programas cooperativos como Pró-Ciências, Pró-Nordeste e Recope, o CADCT totalizou valores efetivamente correspondentes a menos de $1 / 3$ dos recursos previstos em lei para a Fundação.

Esses investimentos do CADCT, ainda que muito aquém das necessidades e demandas do Estado, superam os investimentos feitos por algumas Fundações já consolidadas, a exemplo da Fundação de Amparo à Pesquisa do Estado de Pernambuco (FACEPE), conforme demonstra a FIG. 6

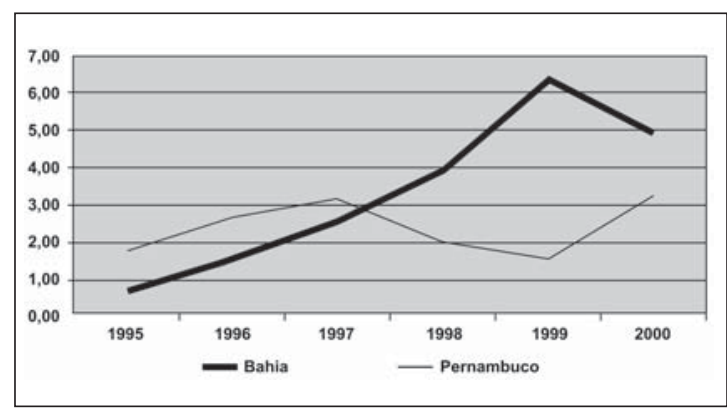

FIGURA 6 - Evolução comparativa de investimentos em C \& $\mathrm{T}$, através dos órgãos de apoio, nos Estados da Bahia e Pernambuco - 1995 a 2000 (recursos do Tesouro Estadual) - (em milhões de R\$) (Valores desembolsados)

FONTE - CADCT. Dados primários; FACEPE. Relatório consolidado.

A criação da Fundação de Amparo à Pesquisa abre uma extraordinária janela de oportunidades para as comunidades técnico-cientifica e empresarial do nosso Estado.

Não só pelo volume dos investimentos públicos em C\&T - a Fundação tem recursos vinculados da ordem de $0,60 \%$ da receita tributária líquida em 2002, e deverá aumentar continuadamente até atingir $1,0 \%$ da receita em 2006 -, como pela maior identidade politica, flexibilidade administrativa e visibilidade social, incontrastavelmente maximizadas em relação a uma superintendência da administração centralizada, como o CADCT o é atualmente, a FAPESB tem como missão básica:

Definir e implementar politicas, prioridades e mecanismos para a concessão de apoio às atividades acadêmicas, científicas, tecnológicas e empresarias de ensino, pesquisa, extensão e inovação em todas as áreas do conhecimento.

Seu objetivo estratégico é buscar a inserção plena da ciência e da tecnologia na solução de problemas econômicos e sociais que afetam o desenvolvimento sustentável da economia da Bahia e o bem-estar da sua população, através da elevação da capacitação tecnológica, do capital intelectual e de tecnologias emergentes, principais vetores do robustecimento econômi- 
co e da elevação do nível da qualidade de vida da população.

Seu programa de ação referencia-se em compreensões básicas do papel da Ciência e Tecnologia (C\&T) e sua inserção na agenda do desenvolvimento social e econômico que envolve:

- C\&T como meios para alcançar benefícios econômicos e sociais e conferir sustentabilidade ao desenvolvimento econômico;

- C\&T como fatores endógenos ao processo de desenvolvimento, numa relação dinâmica e interativa (de múltiplas influências) com os demais fatores socioecônomicos, culturais e históricos.

Esses eixos compreensivos orientam os focos mais abrangentes da ação do órgão, no sentido de:

a) contemplar todas as atividades acadêmicas e de pesquisa e desenvolvimento abrangidas pelas grandes áreas do conhecimento, a saber:

- Ciências Agrárias

- Ciências Biológicas

- Ciências da Saúde

- Ciências Exatas e da Terra

- Engenharia e Ciência da Computação

- Ciências Humanas

- Ciências Sociais Aplicadas

- Lingüistica, Letras e Artes

b) estabelecer prioridades de ação em função dos eixos mais dinâmicos e de maior potencial inovador da economia do
Estado, configurados nas Cadeias Produtivas e Áreas Programas identificadas pelo Programa de Inovação em Áreas Estratégicas e no Programa de Arranjos Produtivos, em execução compartilhada com o Ministério da Ciência e Tecnologia (MCT):

\section{Cadeias/Complexos produtivos}

- Petróleo, Gás Natural e Petroquímica

- Agronegócios

- Metalomecânica e Eletroeletrônica

- Mineração e Metalurgia

- Saúde

- Cultura e Turismo

Áreas Programas

- Serviços Tecnológicos

- Política e Gestão de Ciência e

Tecnologia

\section{Arranjos Produtivos}

- Cacau

- Sisal

- Rochas Ornamentais

- Fruticultura Irrigada

Essas prioridades situam-se num contexto dinâmico e em permanente mutação, o que certamente requererá modificações e ajustes a curto, médio e longo prazos, sobretudo no que tange aos Arranjos Produtivos, identificados, essencialmente, com oportunidades de inovações de alto potencial de negócios ao longo das Cadeias Produtivas.

A nova estrutura da Fundação pode ser visualizada no seu organograma, e a previsão de recursos explicitados nas FIG. 7.

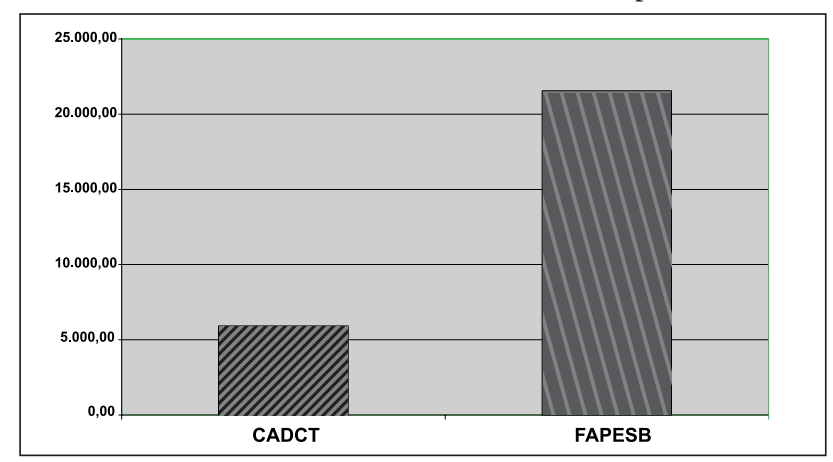

FIGURA 7 - Perspectiva de investimentos da FAPESB - 2001-2002 (em R\$1.000,00)

FONTE - CADCT; FAPESB. Tesouro Estadual. 


\section{ORGANOGRAMA}

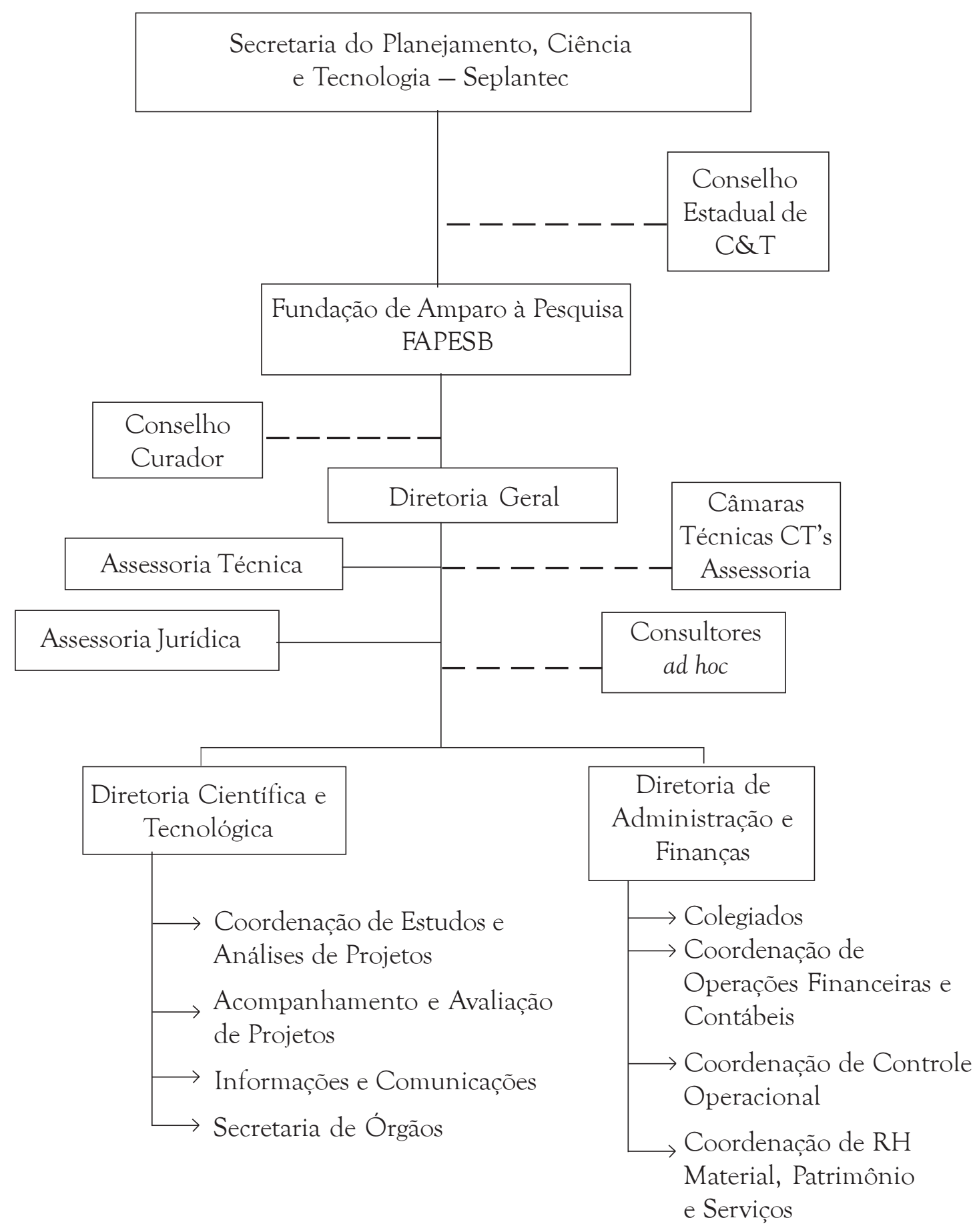


Acresça-se a essas conquistas o fato de que o País também está se robustecendo e alargando seus canais de fluxo de recursos para C\&T com a criação dos Fundos Setoriais (melhor nominados de Fontes Setoriais), reconfigurando um cenário francamente favorável à inovação e, conseqüentemente, à capacidade competitiva da União e dos seus Estados membros. Os recursos previstos para investimentos através desses fundos podem ser vistos no QUADRO 5.

\section{QUADRO 5}

Fundos Setoriais - Orçamento 2001

\begin{tabular}{|lc|}
\hline \multicolumn{1}{|c|}{ FUNDOS } & $\begin{array}{c}\text { ORÇAMENTO } \\
\text { APROVADO } \\
\text { (R\$ milhões) }\end{array}$ \\
\hline Energia $^{*}$ & 80,0 \\
Recursos hidricos $^{*}$ & 26,9 \\
Universidades/Empresa $^{(V e r d e-A m a r e l o)}{ }^{*}$ & 192,0 \\
Mineral $^{*}$ & 2,7 \\
Espacial $^{*}$ & 5,4 \\
Transportes $^{*}$ & 8,0 \\
Infra-estrutura (Fundo dos Fundos) $^{*}$ & 138,5 \\
Petróleo $^{*}$ & 151,1 \\
Informática* $^{*}$ & 44,0 \\
Funtel $^{* 1}$ & 239,0 \\
Saúde $^{* 2}$ & 90,0 \\
Agronegócios $^{* 2}$ & 90,0 \\
Biotecnologia $^{* 2}$ & 26,0 \\
Aeronáutico $^{* 2}$ & 13,0 \\
\hline
\end{tabular}

Fonte - MCT

* Fundos implementados

${ }^{* 1}$ Fundo administrado pelo Ministério das Comunicações

*2 Fundos aprovados

A existência da FAPESB eleva substancialmente a capacidade competitiva da Bahia na captação de recursos nessas fontes setoriais, visto que muitas dessas fontes têm percentuais de $20 \%$ a $40 \%$ cativos para investimentos nos Estados do Nordeste, alguns deles em operações cruzadas com contrapartidas locais de um para um real investido.
Nessas bases, já foi negociado entre o CADCT e o CNPq/MCT, para execução pela FAPESB, um vigoroso programa de atração e fixação de doutores no Estado.

Configura-se, portanto, um cenário promissor de oportunidades para que a Bahia venha a dar um excepcional salto rumo ao desenvolvimento sustentável da economia e ao bemestar da sua população, através da elevação da capacitação tecnológica, do capital intelectual e de tecnologias emergentes, principais vetores do robustecimento econômico e da elevação da qualidade de vida da população.

\section{Referências}

BARROS, Fernando A. F. de. Confrontos e contrastes regionais da ciência e tecnologia no Brasil. Brasilia: Paralelo 15; UNB, 1999.

CADCT/SEPLANTEC. CADCT 10 anos. Salvador: Solisluna, 2001.

CADCT/SEPLANTEC. Inovação Bahia: programa de inovação em áreas estratégicas para o Estado da Bahia. Salvador: Solisluna, 2001.

DICKSON, David. Alternative technology and the politics of technical change. Glasgow: Collins Sons \& Co, 1977.

ENZENSBERGER, Hans Magnus. A ressurreição triunfal da crença no progresso nas ciências. Folha de S. Paulo, São Paulo, 9 set. 2001. Caderno Mais.

FREEMAN, Chris; SOET, Luc. The economics of industrial innovation. 3. ed. London: Pinter, 1997.

HAWKING, Stephen. O universo numa casca de noz. Tradução de Ivo Korytowsky. São Paulo: Mandarim, 2001.

LASTRES, M. Helena M. The advanced materials revolution and the Japanese system of innovation. St. Martin's Press, 1994.

PORTER, Michael E. Competição = On competition: estratégias competitivas essenciais. Tradução de Afonso Celso da Cunha Serra. 2. ed. Rio de Janeiro: Campus, 1999.

TEICH, Albert H. Technology and the future. 7. ed. New York, 1997.

VARGAS, Milton. História da técnica e da tecnologia no Brasil. São Paulo: Ed. Estadual Paulista, 1994. 